-
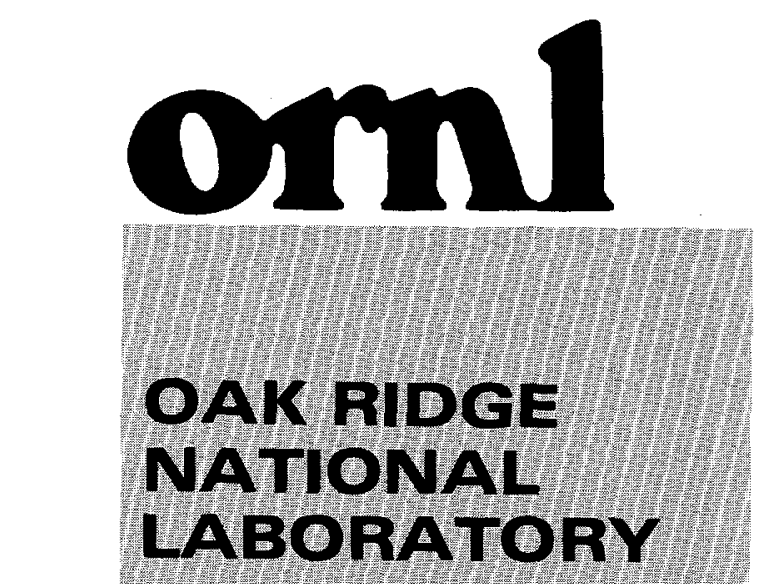

tog the $=0$

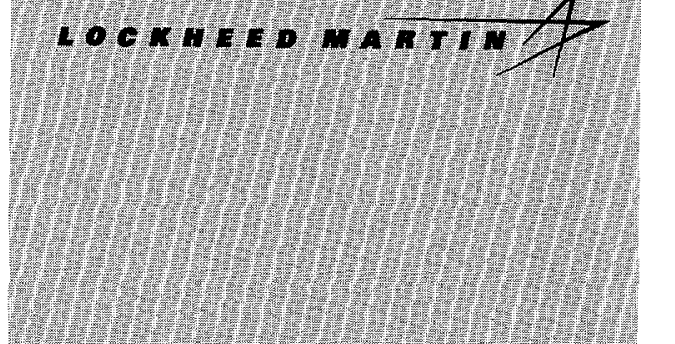

WWIGEO AWD OPERATED BY LOCKHEED MARTIN ENEROY RESEARCH CORPORATION FOB THE UNTED STATES DEPARTUENT OF ENERCY

\section{ORNL/M-6663}

APPROVED FOR PUBLIC RELEASE

C/ORNL97-0471

\author{
CRADA Final Report \\ for \\ CRADA Number ORNL97-0471 \\ SINTERED REACTION BONDED \\ SILICON PARTS BY MICROWAVE \\ NITRIDATION COMBINED \\ WITH GAS-PRESSURE SINTERING
}

T. N. Tiegs and J. O. Kiggans

Oak Ridge National Laboratory

\author{
B. Mikijelj \\ Ceradyne, Inc.
}

\section{RECEIVED}

\section{JAN 131999 Prepared by the}

O S T I Oak Ridge, Tennessee 37831 managed by

Lockheed Martin Energy Research Corporation for the

U.S. Department of Energy under contract DE-AC05-96OR22464

APPROVED FOR PUBLIC RELEASE 
This report has been reproduced from the best available copy.

Reports are available to the public from the following source.

National Technical Information Service

5285 Port Royal Road

Springfield, VA 22161

Telephone 703-605-6000 (1-800-553-6847)

TDD 703-487-4639

Fax 703-605-6900

E-mail orders@ntis.fedworld.gov

Web site http://www.ntis.gov/ordering.htm

Reports are available to U.S. Department of Energy (DOE) employees, DOE contractors, Energy Technology Data Exchange (ETDE) representatives, and International Nuclear Information System (INIS) representatives from the following source.

Office of Scientific and Technical Information

P.O. Box 62

Oak Ridge, TN 37831

Telephone 423-576-8401

Fax 423-576-5728

E-mail reports@adonis.osti.gov

Web site http://www.osti.gov/products/sources.html

Reports produced after January 1,1996 , are generally available via the DOE Information Bridge.

Web site http://www.doe.gov/bridge 


\section{DISCLAIMER}

Portions of this document may be illegible in electronic image products. Images are produced from the best available original document. 


\author{
CRADA Final Report \\ for \\ CRADA Number ORNL97-0471
}

\title{
SINTERED REACTION BONDED SILICON PARTS BY MICROWAVE NITRIDATION COMBINED WITH GAS-PRESSURE SINTERING
}

T. N. Tiegs and J. O. Kiggans

Oak Ridge National Laboratory

\author{
B. Mikijelj \\ Ceradyne, Inc. \\ Prepared by the \\ Oak Ridge National Laboratory \\ Oak Ridge, Tennessee 37831 \\ managed by \\ Lockheed Martin Energy Research Corporation \\ for the \\ U.S. Department of Energy \\ under contract DE-AC05-96OR22464
}

Research sponsored by the U.S. Department of Energy, Assistant Secretary for Energy Efficiency and Renewable Energy, Office of Transportation Technologies, as part of the Heavy Vehicle Propulsion System Materials Program, under contract DE-AC05-96OR22464 with Lockheed Martin Energy Research Corporation

\section{Unlimited Distribution}



INTRODUCTION

RESULTS.

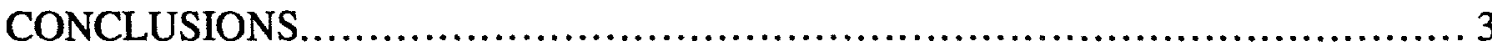

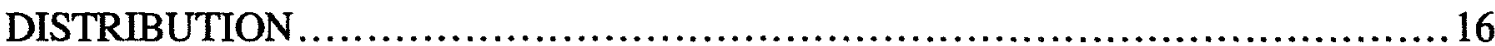

\section{FIGURES}

Figure 1 Basic flowchart for the gelcasting process.............................. 4

Figure 2 Initial gelcast trials showed premature gelation of silicon and monomer(s) occurred during milling operations. Partial mill jar (left) shows gelled Si slurry and loose milling media .............................................. 5

Figure 3 Gelcast tests performed to evaluate effect of monomer and Si type on gel initiation........................................................... 6

Figure 4 Gel initiation time varied for different Si powders and monomers. As-received Globe Si was the most reactive material tested

Figure 5 The addition of inhibitor can extend processing time for $\mathrm{Si}+$ monomer slurries. Inhibitor addition delayed gel formation with Ceradyne Si during milling operation 8

Figure 6 Inhibitor delayed initiation of gel formation with Ceradyne Si powder. Action of the inhibitor significant at 100 to $250 \mathrm{ppm}$.

Figure 7 Strengths of the green preforms dependent on gel composition. Effect of inhibitor addition varied with gel system................................. 10

Figure 8 Strength of sintered materials comparable for PEG and MAM-PEG gels.......11

Figure 9 Photo of silicon test parts provide by Ceradyne for MW nitridation trials ....12

Figure 10 Schematic of MW nitridation package ....................................12

Figure 11 Photo of Ceradyne parts nitrided by $\mathrm{MW}$ heating in experiment $2 \ldots \ldots \ldots \ldots \ldots 13$

Figure 12 Photo of slices from three Ceradyne parts which were partially nitrided using MW heating. The slices originated from samples that were classified by Ceradyne as high, medium, or low density $(H, M, L)$ prior to nitridation. 13

Figure 13 Power - Temperature curves for MW nitridation scale-up run with SiC-felt crucible walls....................................................... 14

Figure 14 Photo of slices from three Ceradyne parts which were nitrided using MW heating and 1 part nitrided by conventional heating (C). The MW slices originated from green preforms that were classified by Ceradyne as high, medium, or low $(\mathrm{H}, \mathrm{M}, \mathrm{L})$ density prior to nitridation........................ 14

Figure 15 Power - Temperature curves for MW nitridation scale-up run with 125 samples................................................................... 15

Figure 16 Photo showing the top layer (two total) of samples in which 125 samples $(5.8 \mathrm{~kg})$ nitrided using $M W$ heating

\section{TABLES}

Table 1 Summary of nitridation experiments 


\section{SINTERED REACTION BONDED SILICON PARTS BY MICROWAVE NITRIDATION COMBINED WITH GAS-PRESSURE SINTERING}

\section{INTRODUCTION}

The major reason for the failure of the introduction of ceramics into many applications has been cost of components. This is most noticeable in the transportation vehicle engine industry where ceramics would provide lighter, more fuel-efficient and less polluting engines. Silicon nitride ceramics are the leading candidate materials for high temperature structural applications because of their combination of excellent strength, fracture toughness, wear resistance, thermal shock tolerance and high temperature properties. Development has traditionally been directed towards materials with superior strength, fracture toughness, wear behavior, and creep resistance with cost a secondary consideration. Consequently, traditional materials tend to be very expensive and are not competitive with metal parts on a replacement basis in many applications. Sintered reaction-bonded silicon nitride (SRBSN) is a cost-effective material that is receiving increased industrial interest for structural applications at temperatures $<1200^{\circ} \mathrm{C}$. Compared to traditionally processed SRBSN ceramics, microwave processing can result in improved temperature uniformity, reduction of the total reaction time, and reaction in a more controlled environment around the parts.

Development of SRBSN materials for structural applications was being researched by ORNL and Ceradyne. The ORNL work was done under the Heavy Duty Transport Propulsion Project. The focus of that work involved up-scaling of the microwave process to large batch sizes. Ceradyne is a manufacturer of SRBSN parts using conventional forming processes to manufacture parts and conventional heating for nitridation followed by gas-pressure sintering.

The cooperative project was a joint development program between Ceradyne and Oak Ridge National Laboratory through Lockheed Martin Energy Research (LMER). Cooperative work was of benefit to both parties. ORNL was able to assess the effect of the microwave nitridation process coupled with gas-pressure sintering for fabrication of parts for advanced diesel engines. Ceradyne gained access to gelcasting expertise and microwave facilities and experience for the nitridation of SRBSN materials. The broad objective of the CRADA between Ceradyne and ORNL was to (1) examine the applicability of the gelcasting technology to fabricate parts from SRBSN, and (2) to assess the effect of the microwave nitridation of silicon process coupled with gas-pressure sintering for fabrication of parts for advanced diesel engines.

\section{RESULTS}

Gelcasting of Silicon - The first phase of this project dealt with the gelcast forming of a batch of silicon powders provided by Ceradyne. A basic flow sheet for the gelcasting process is shown in Figure 1. Initial testing revealed that Si-containing slurries can under go premature gelling during the milling operations as illustrated in Figure 2. Consequently, testing was done to assess the effect of Si type and gel system on the gelling time as shown in Figure 3. As-received Globe $\mathrm{Si}$ was used as a standard for comparison purposes. The effect of gel system on gel time is shown in Figure 4. To compensate for premature gelling, a gel inhibitor was introduced into the slurries which improved the inhibition to gelation as shown in Figure 5. The effect of the inhibitor on gel time is shown in Figure 6, which indicated that inhibitors levels of 100 to $250 \mathrm{ppm}$ were necessary to delay gelling for 
significant times. The effect of the gel system and inhibitor on green strength is shown in Figure 7.

From the green strength results and visual observations, samples were fabricated in which three gelcast monomer systems (PEG, MAM:PEG 3:1, and MAM:PEG 6:1) were tested with one batch of Ceradyne powder. Slurries containing $47 \mathrm{vol}$. \% of silicon powders were prepared by ball milling techniques. Plates $(10$ by 10 by $0.7 \mathrm{~cm})$, discs $(4 \mathrm{~cm}$ diameter by $0.7 \mathrm{~cm}$ thick), and a tensile rod shape were cast using the three gelcast monomer systems. Gelcast samples were shipped to Ceradyne for nitridation, gaspressure sintering and machining into mechanical test specimens. The flexural strength of the samples is shown in Figure 8.

Microwave Nitridation - The second phase of the Ceradyne CRADA was the nitridation of silicon preforms (supplied by Ceradyne) by microwave (MW) heating at ORNL. Table 1 lists the 8 nitridation experiments that were performed using silicon test parts provided by Ceradyne. Figure 9 is photograph of three Ceradyne parts that were nitrided in the MW nitridation trials. Actual tests were made with four different sizes of this basic geometry. The purpose of the nitridation experiments was twofold: (1) to determine the proper sample crucible materials needed for processing the Ceradyne parts, and (2) to determine the proper heating cycle needed for complete MW nitridation. Figure 10 is a generic schematic of an insulation package and sample crucible to help understand discussions regarding the experiments that were performed.

The first two MW nitridation experiments, 1 and 2 (Table 1), involving 30 and 42 samples, respectively, used an inner crucible consisting of silicon nitride setters and boron nitride (BN) walls (not attached to each other). Samples having three different green densities, labeled as high, medium, and low were processed in the second experiment. The heating cycles for the two experiments were 16 and 24 hours, respectively. The data shows that the average weight gains were low compared to the theoretical weight gain expected for full nitridation. The low nitridation indicated that the heating cycles were too short. In both experiments, samples adjacent to the $\mathrm{BN}$ crucible walls gained less weight than the center samples, indicating that hybrid heating by the crucible is required for even nitridation. Figure 11 is a photograph of the samples nitrided in experiment 2 . Figure 12 shows crosssection views of several of the samples nitrided in experiment 2 . The photograph shows that the edges of all samples were fully nitrided, however the centers of the samples were not fully nitrided. Higher nitridation was observed in the low density samples, and lower nitridation was seen as the density of the parts were increased, $\mathrm{L}>\mathrm{M}>\mathrm{H}$. These findings were expected, since the surface of the samples has easy access to nitrogen, and nitrogen diffuses less readily through the samples of increasing density. Since the surfaces of the Ceradyne samples seal away nitrogen from the interior during nitridation, very short nitridation cycles were not possible.

The third MW nitridation experiment utilized a hybrid sample crucible containing low density SiC-felt walls and silicon nitride setters. The length of the nitridation run was increased to $35 \mathrm{~h}$. Very good nitridation was obtained in this run; however, the microwave power control for this furnace set-up resulted in very large temperature surges during nitridation, as shown in Figure 13. The use of low density SiC hybrid crucible walls shows promise and will undergo further evaluation. A conventional nitridation run, experiment 4, was performed, as a control, using a graphite furnace and a $35 \mathrm{~h}$ heating cycle. The $56.6 \%$ nitridation weight gain obtained was comparable to the microwave run. Figure 14 is a photograph of several of the samples nitrided in experiments 3 and 4 . This photograph shows that a much more complete nitridation was performed for all sample types, than was observed in samples processed in experiment 2. 
Experiment 5 was the third experimental set-up tested for microwave nitridation of Ceradyne parts. This set-up was chosen because of unpublished studies showing that alumina is a good possibility for a hybrid microwave heater at high temperatures, as in a nitridation treatment. Forty samples were nitrided in a $20 \mathrm{~h}$ cycle. The short nitridation time was chosen because of the more unpredictable nature of this experiment. An average of a median weight gain was obtained, but there was a large variation in weight gains, in particular in areas adjacent to edge samples. This set-up represents possibly the quickest approach for an off-the-shelf commercial MW furnace set-up; but, as with the SiC felt, requires more development work.

Experiments 6,7, and 8 utilized the last set-up, and the final choice for the sample crucible for the nitridation of Ceradyne parts. The crucible consisted of either silicon nitride or boron nitride setters (both shown to be acceptable) and crucible walls made of Ceradyne silicon nitride materials (nitrided samples utilized for walls here, in lieu of casting wall materials). These three nitridation experiments represented scale-up from 37, to 54, to 125 parts. The first trial with 37 samples was done to test MW furnace power control and heating uniformity. The good furnace control and acceptable uniformity led to the next two scale-up runs. The final run had a $32 \mathrm{~h}$ heating cycle and the average weight gain was $55.7 \%$, slightly less than the theoretical. It appears a longer hold at $1400^{\circ} \mathrm{C}$ is necessary to achieve optimum nitridation. Figure 15 is a temperature versus microwave power curve from data collected from experiment 8 . The data shows the good sample temperature control and the minimal power fluctuations. Figure 16 is a photograph of the samples and microwave insulation package upon completion of experiment 8.

\section{CONCLUSIONS}

The following conclusions can be made from the work performed under the CRADA:

1. Gelcasting is a viable method to fabricate SRBSN parts using Ceradyne Si mixtures. However, the technique requires further development prior to being put into commercial use.

2. Microwave heating can be utilized to nitride multiple SRBSN parts. Scale-up of the process to fabricate several kilograms of material (up to $6 \mathrm{~kg}$ ) per furnace run was demonstrated. 


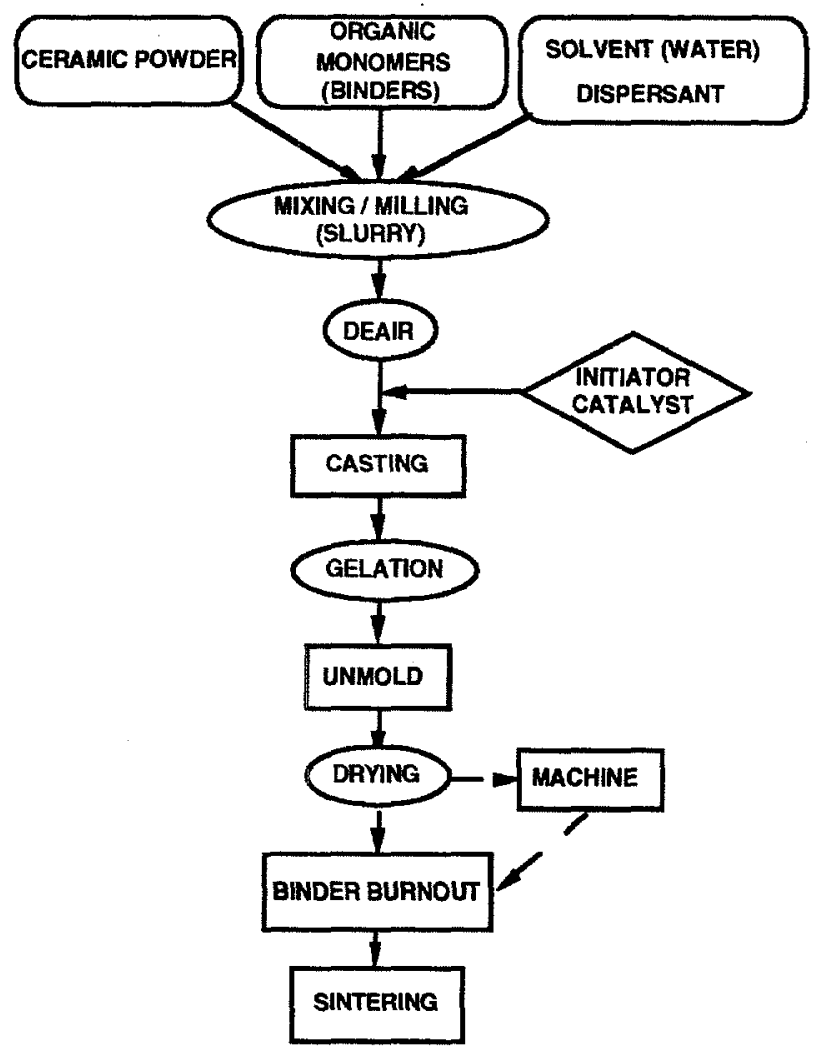

Figure 1 Basic flowchart for the gelcasting process. 


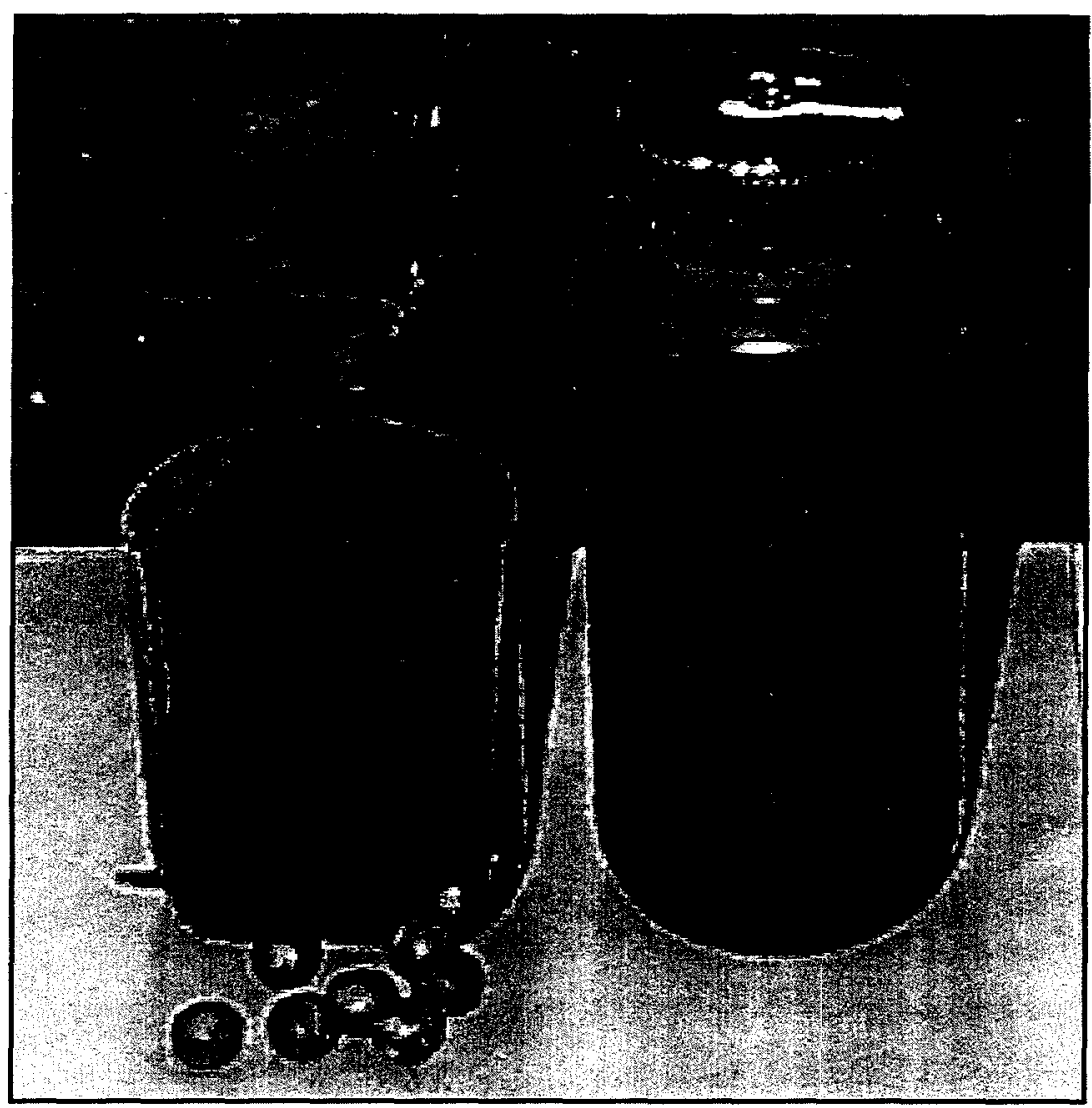

Figure 2. Initial gelcast trials showed premature gelation of silicon and monomer(s) occurred during milling operations. Partial mill jar (left) shows gelled Si slurry and loose milling media. 


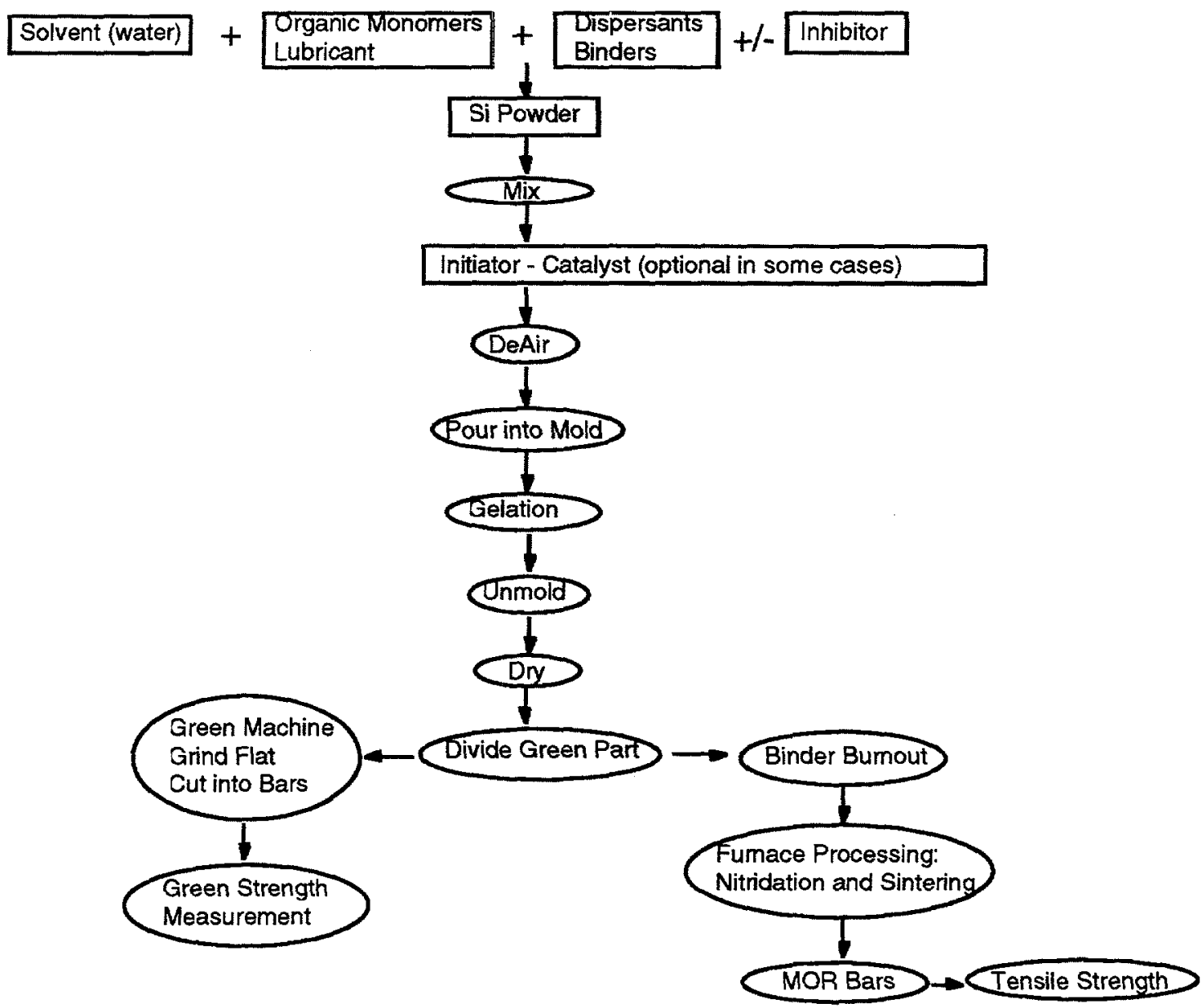

Figure 3. Gelcast tests performed to evaluate effect of monomer and Si type on gel initiation. 


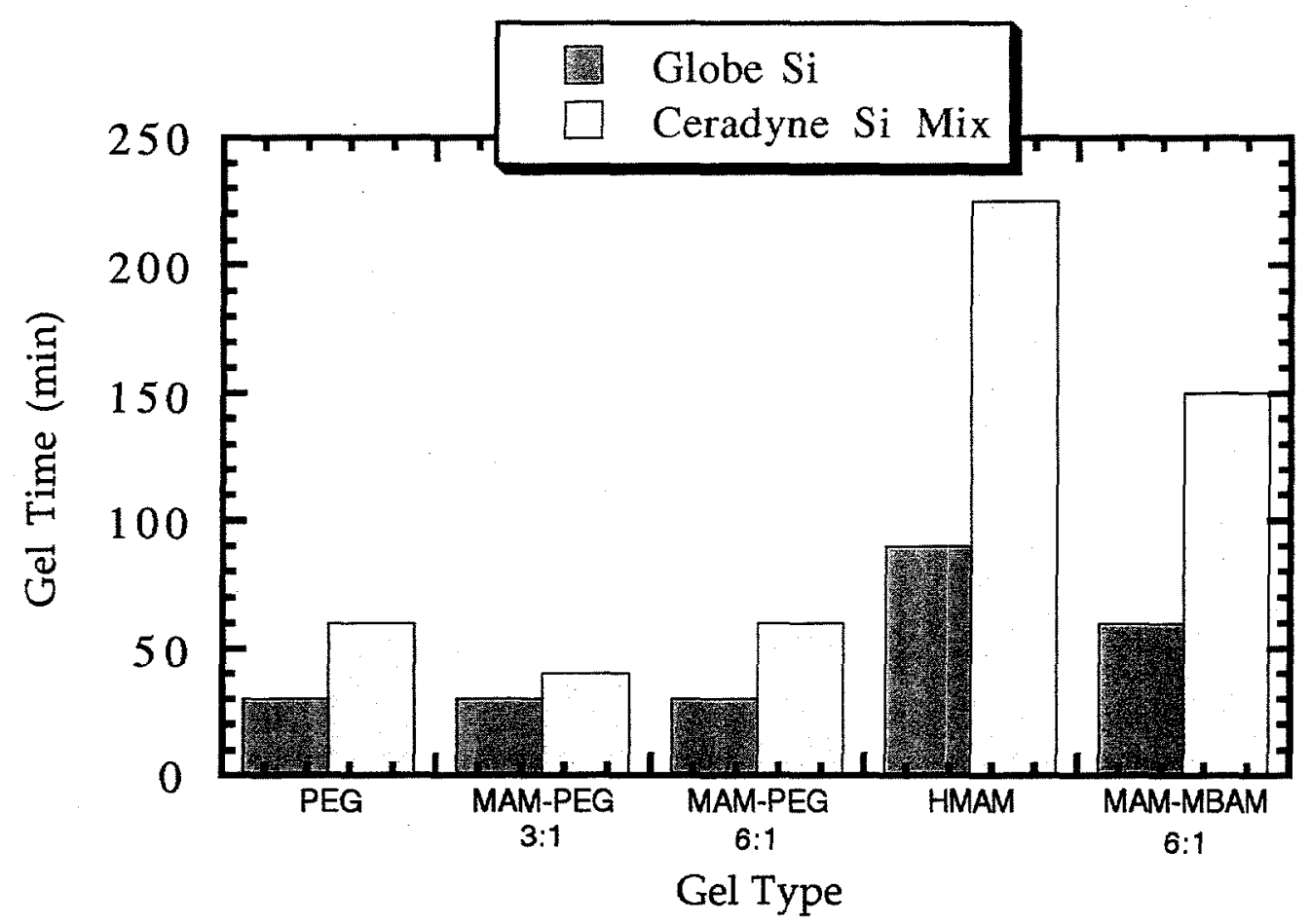

Figure 4. Gel initiation time varied for different Si powders and monomers. As-received Globe Si was the most reactive material tested. 


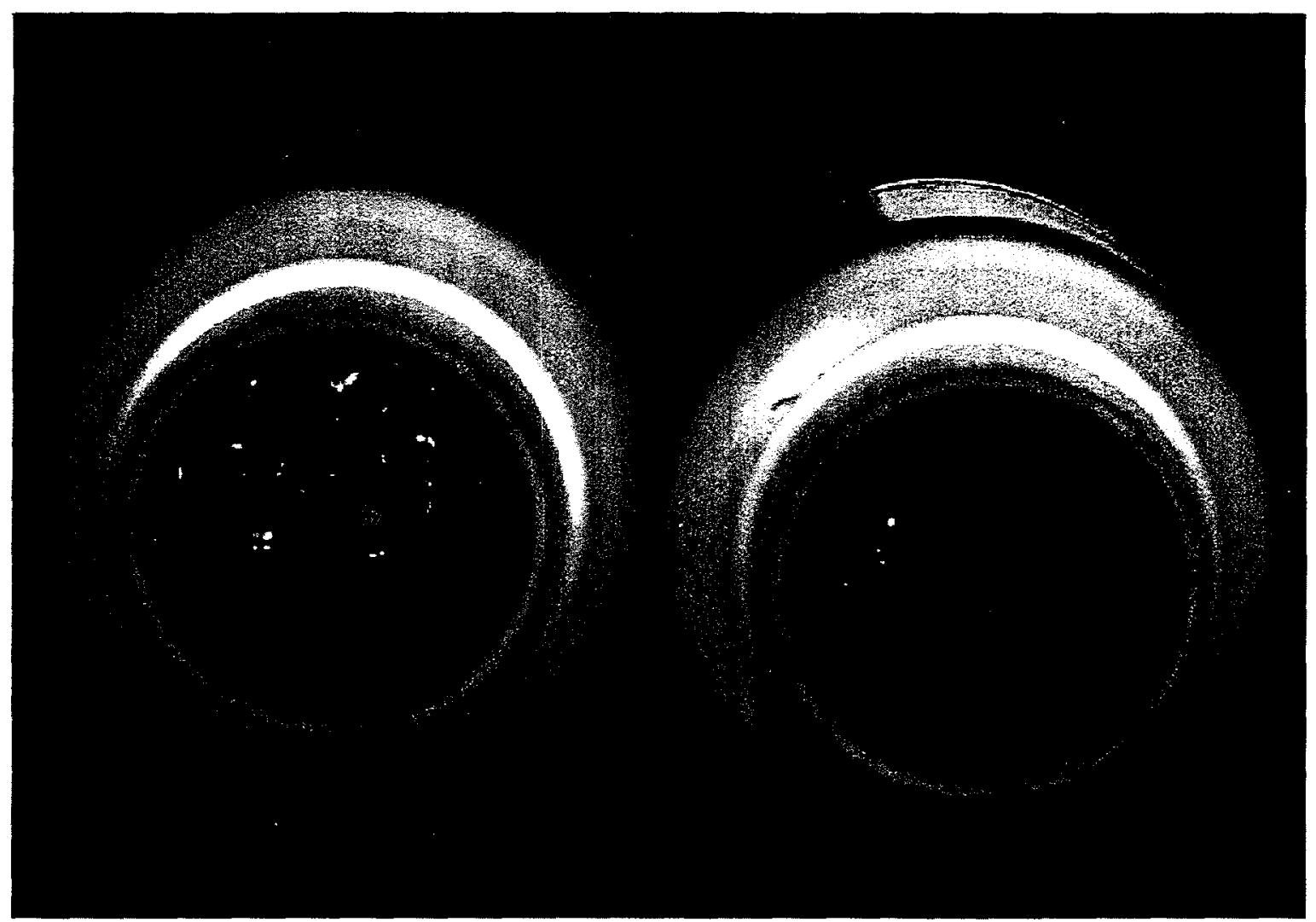

Figure 5. The addition of inhibitor can extend processing time for $\mathrm{Si}+$ monomer slurries. Inhibitor addition delayed gel formation with Ceradyne Si during milling operation. 


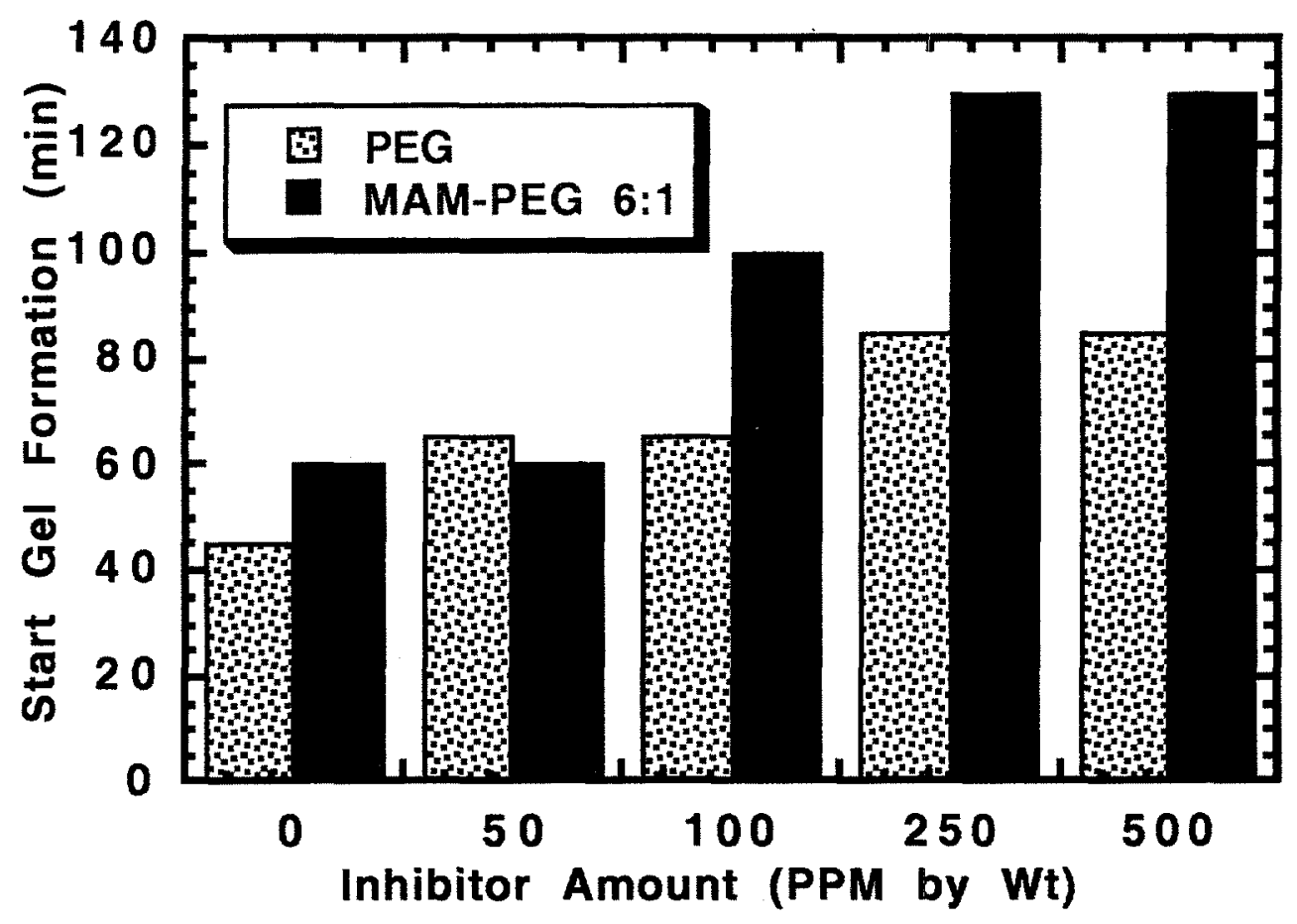

Figure 6. Inhibitor delayed initiation of gel formation with Ceradyne Si powder. Action of the inhibitor significant at 100 to $250 \mathrm{ppm}$. 


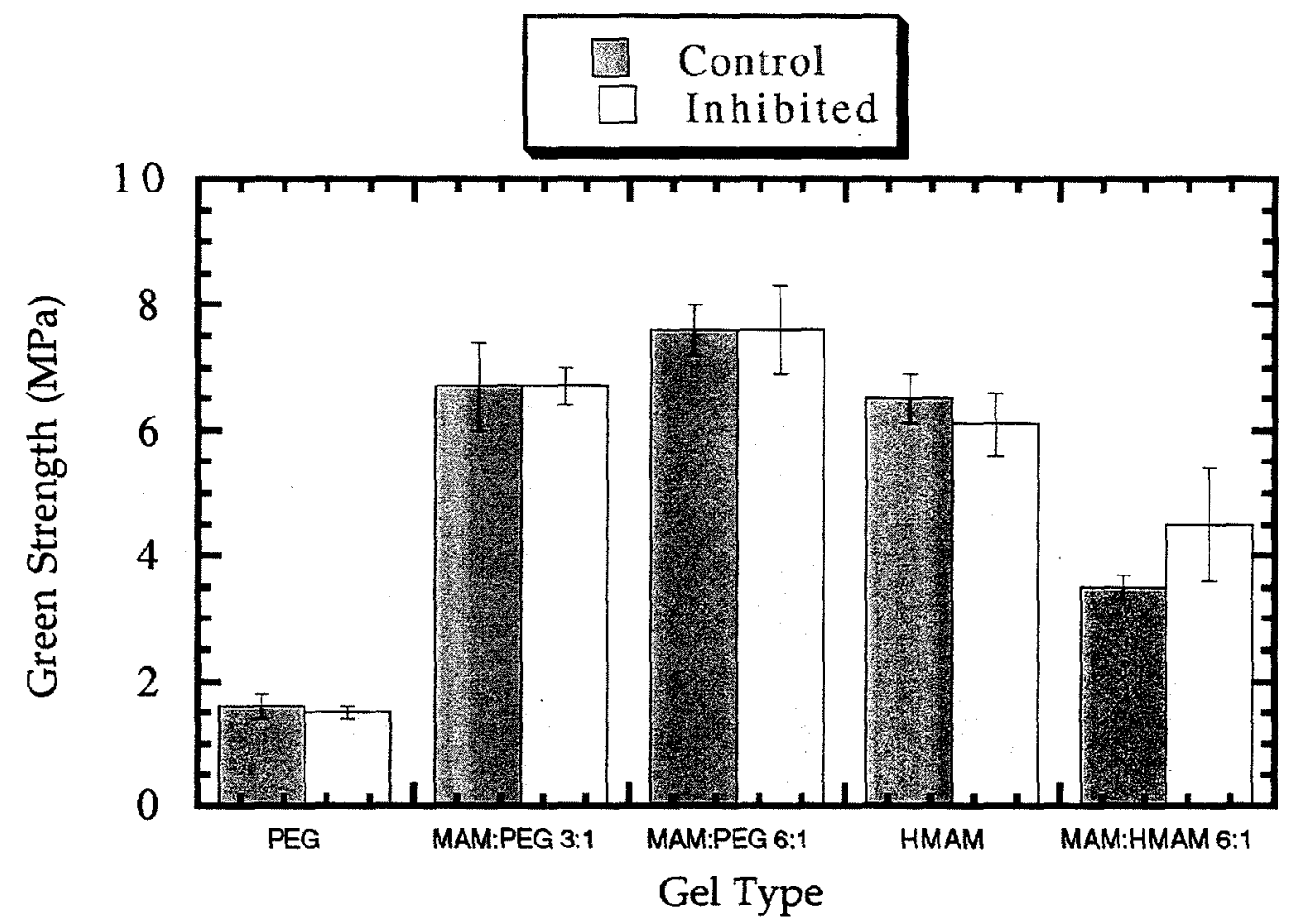

Figure 7. Strengths of the green preforms dependent on gel composition. Effect of inhibitor addition varied with gel system. 


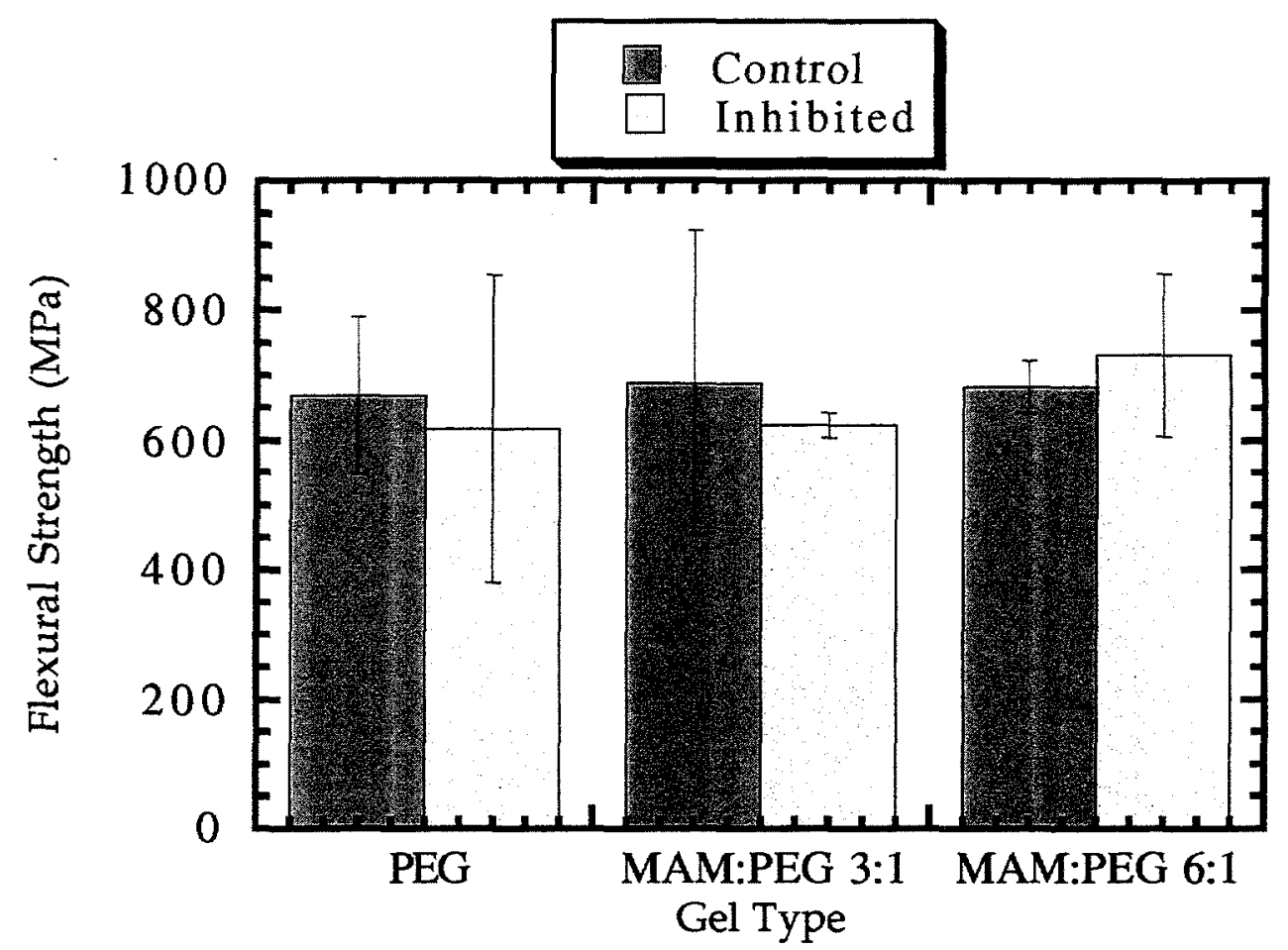

Figure 8. Strength of sintered materials comparable for PEG and MAM-PEG gels.

Table 1. Summary of nitridation experiments

\begin{tabular}{|c|c|c|c|c|c|c|c|c|}
\hline Exp. \# & $\begin{array}{c}\text { Nit. } \\
\text { Method }\end{array}$ & $\begin{array}{c}\text { Heat. } \\
\text { Cycle } \\
(\mathrm{h})\end{array}$ & $\begin{array}{c}\text { Peak Temp. } \\
\left({ }^{\circ} \mathrm{C}\right)\end{array}$ & Crucible Type & \# Samp. & $\begin{array}{c}\text { Samp. } \\
\text { Space } \\
(\mathrm{cm})\end{array}$ & $\begin{array}{c}\text { Avg. } \\
\text { Nitridation* } \\
(\%)\end{array}$ & $\begin{array}{c}\text { Std. Dev. } \\
(\%)\end{array}$ \\
\hline 1 & MW & 16 & 1450 & Si3N4 -BN & 30 & 1.3 & 85.6 & 0.013 \\
\hline 2 & MW & 24 & 1450 & Si3N4 -BN & 42 & 0.5 & 90.9 & 2.98 \\
\hline 3 & MW & 35 & 1450 & Si3N4 - SiC Felt & 42 & 0.5 & 99.8 & 0.0022 \\
\hline 4 & Conv & 35 & 1450 & Graphite-A12O3 & 3 & 0.5 & 99.5 & 0.0024 \\
\hline 5 & MW & 20 & 1450 & Si3N4 -Al2O3 & 40 & 0.5 & 92.6 & 0.029 \\
\hline 6 & MW & 20 & 1450 & Si3N4 -Samples & 37 & 0.3 & 92.1 & 0.038 \\
\hline 7 & MW & 32 & 1425 & Si3N4 -Samples & 54 & 0.3 & 100 & 0.002 \\
\hline 8 & MW & 32 & 1425 & BN -Samples & 125 & 0.3 & 97.7 & 0.008 \\
\hline
\end{tabular}

*\% wt. gain $/ \%$ theoretical wt. gain 


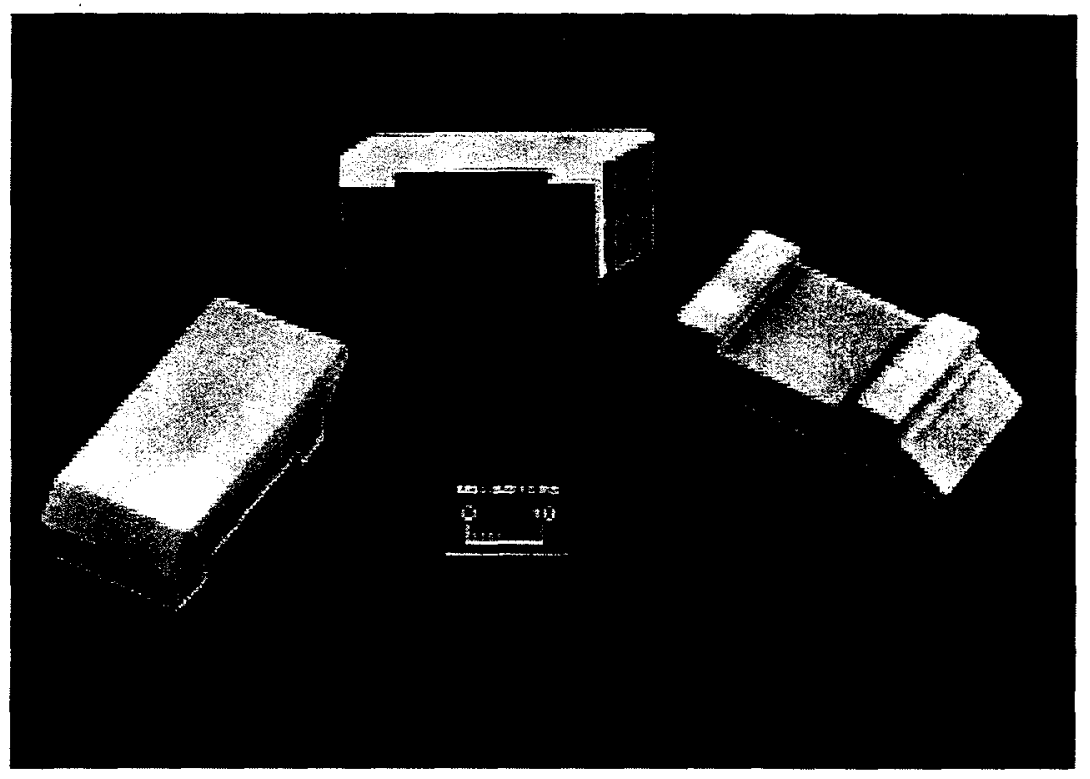

Figure 9. Photo of silicon test parts provide by Ceradyne for MW nitridation trials.

\section{Cross Section View Of Microwave Insulation Package}

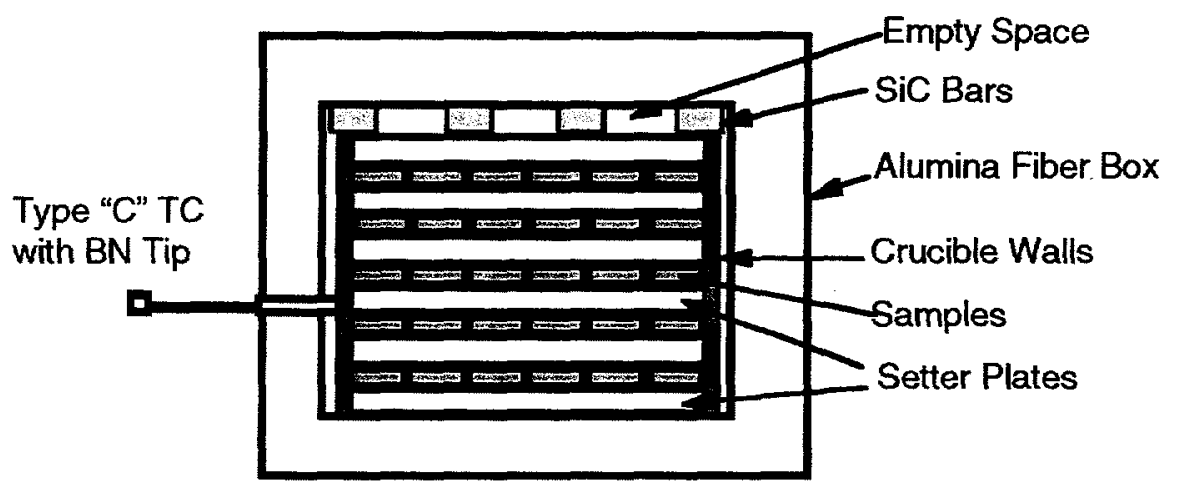

Figure 10. Schematic of MW nitridation package 


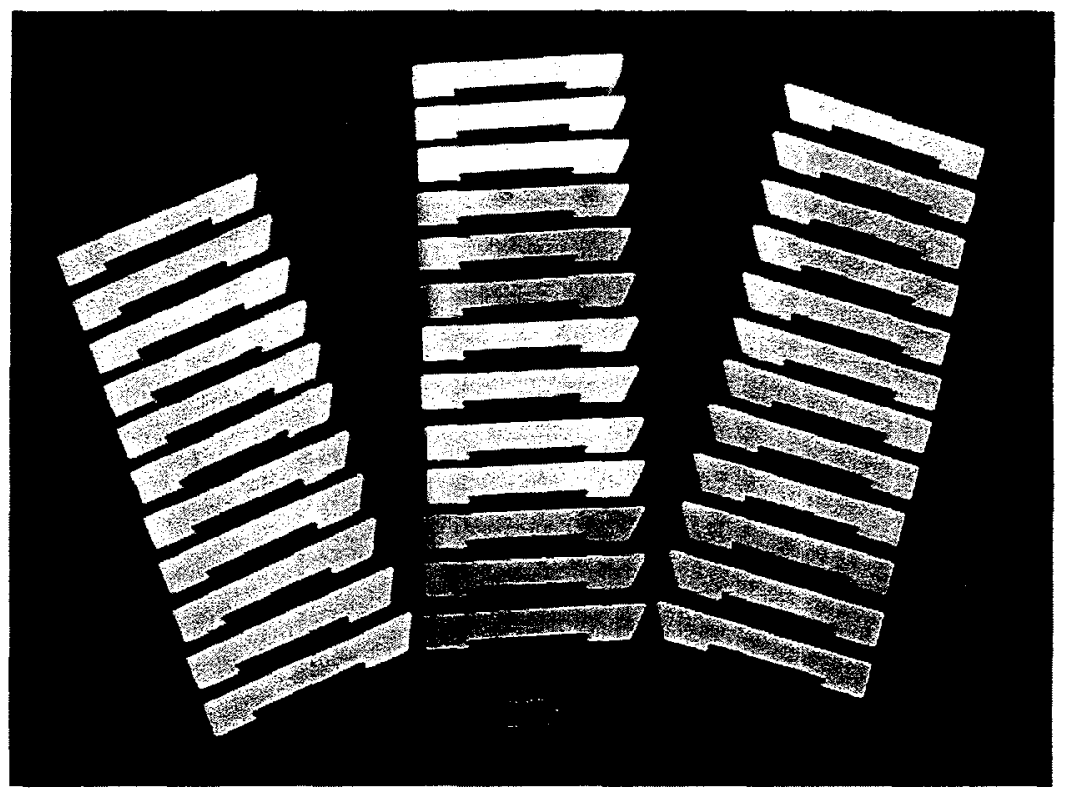

Figure 11. Photo of Ceradyne parts nitrided by MW heating in experiment 2.

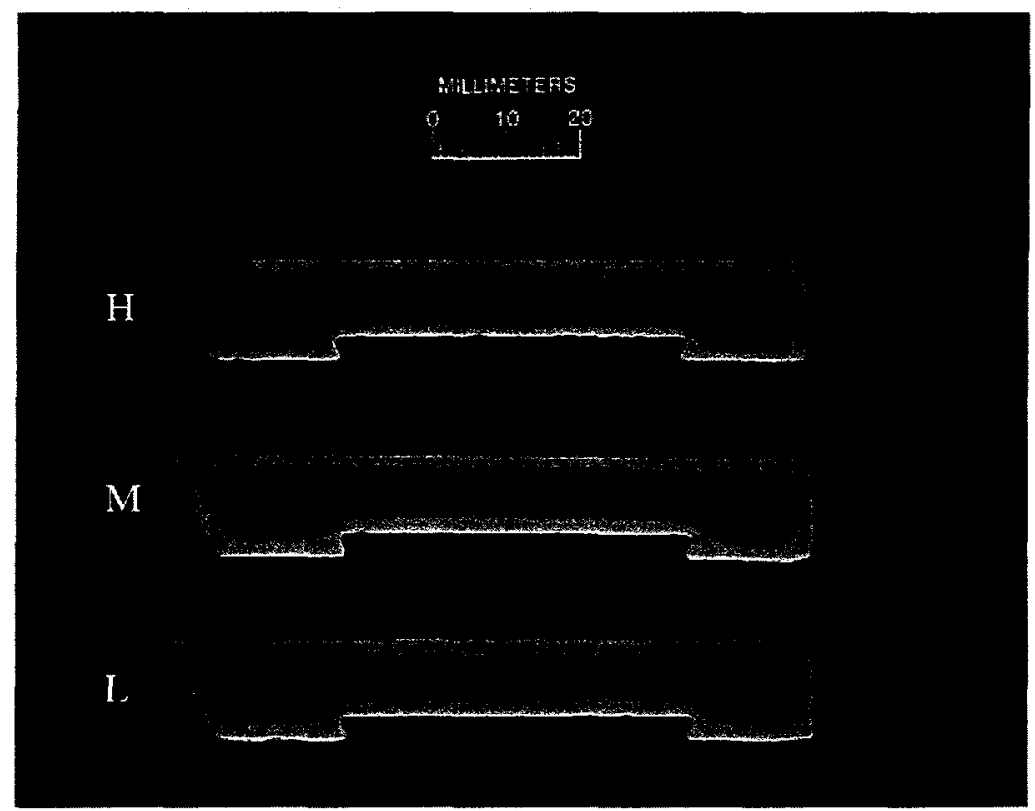

Figure 12. Photo of slices from three Ceradyne parts which were partially nitrided using MW heating. The slices originated from samples that were classified by Ceradyne as high, medium, or low density $(\mathrm{H}, \mathrm{M}, \mathrm{L})$ prior to nitridation. 


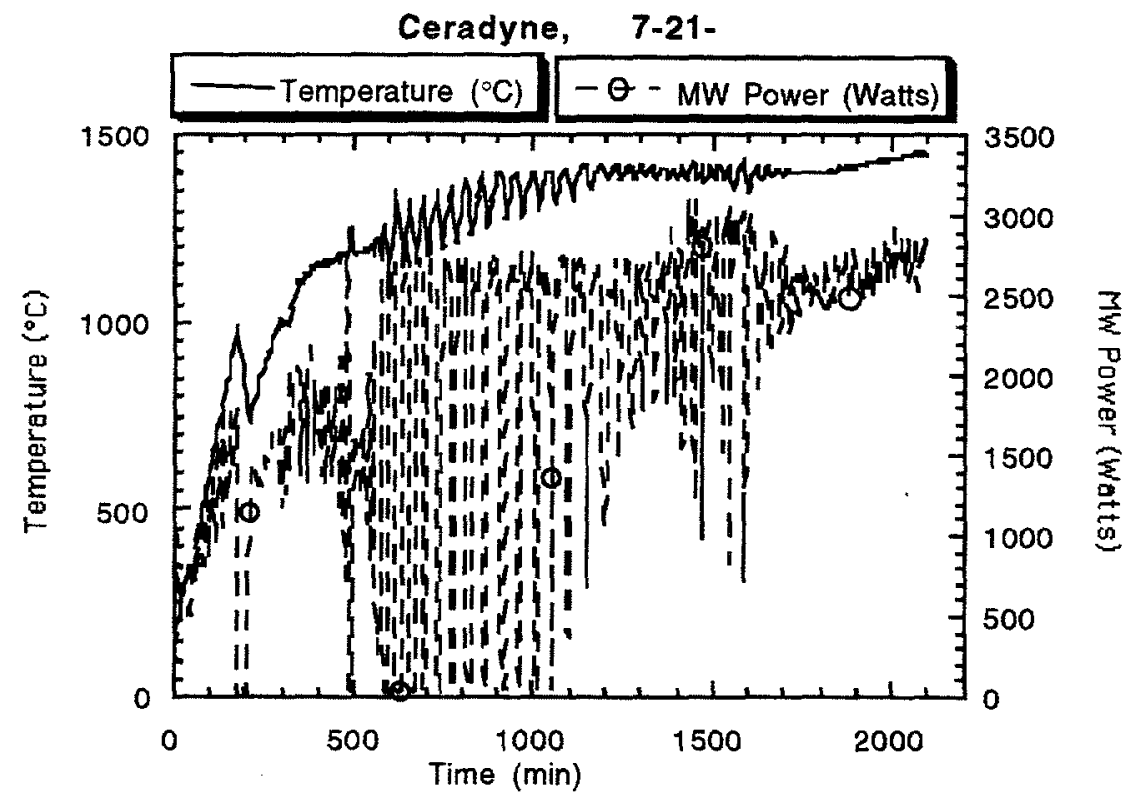

Figure 13. Power - Temperature curves for MW nitridation scale-up run with SiC-felt crucible walls.

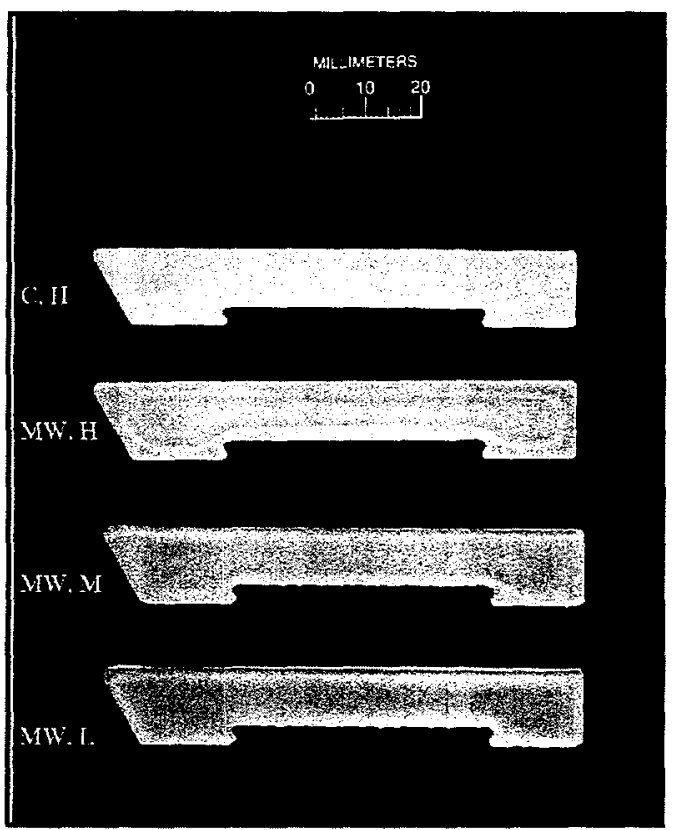

Figure 14. Photo of slices from three Ceradyne parts which were nitrided using MW heating and 1 part nitrided by conventional heating $(\mathrm{C})$. The $\mathrm{MW}$ slices originated from green preforms that were classified by Ceradyne as high, medium, or low $(\mathrm{H}, \mathrm{M}, \mathrm{L})$ density prior to nitridation. 


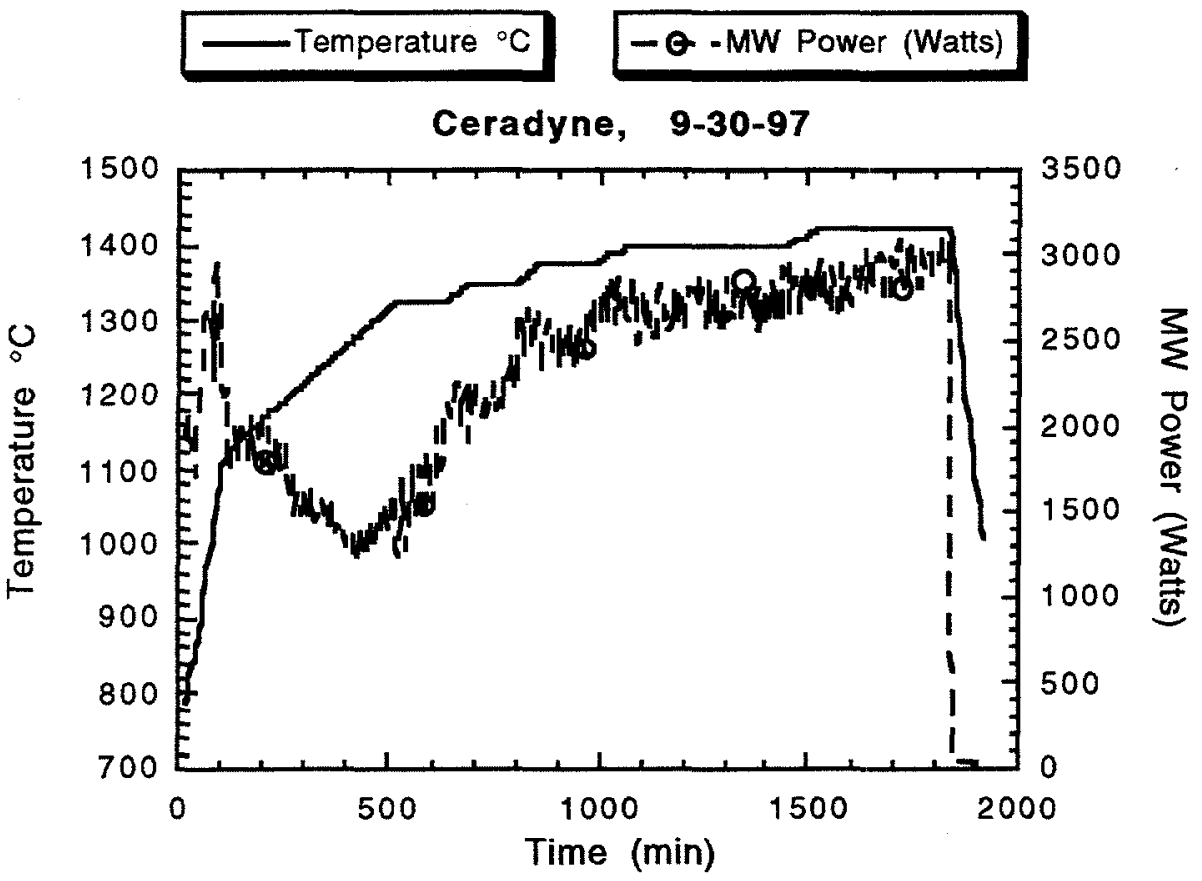

Figure 15. Power - Temperature curves for MW nitridation scale-up run with 125 samples.

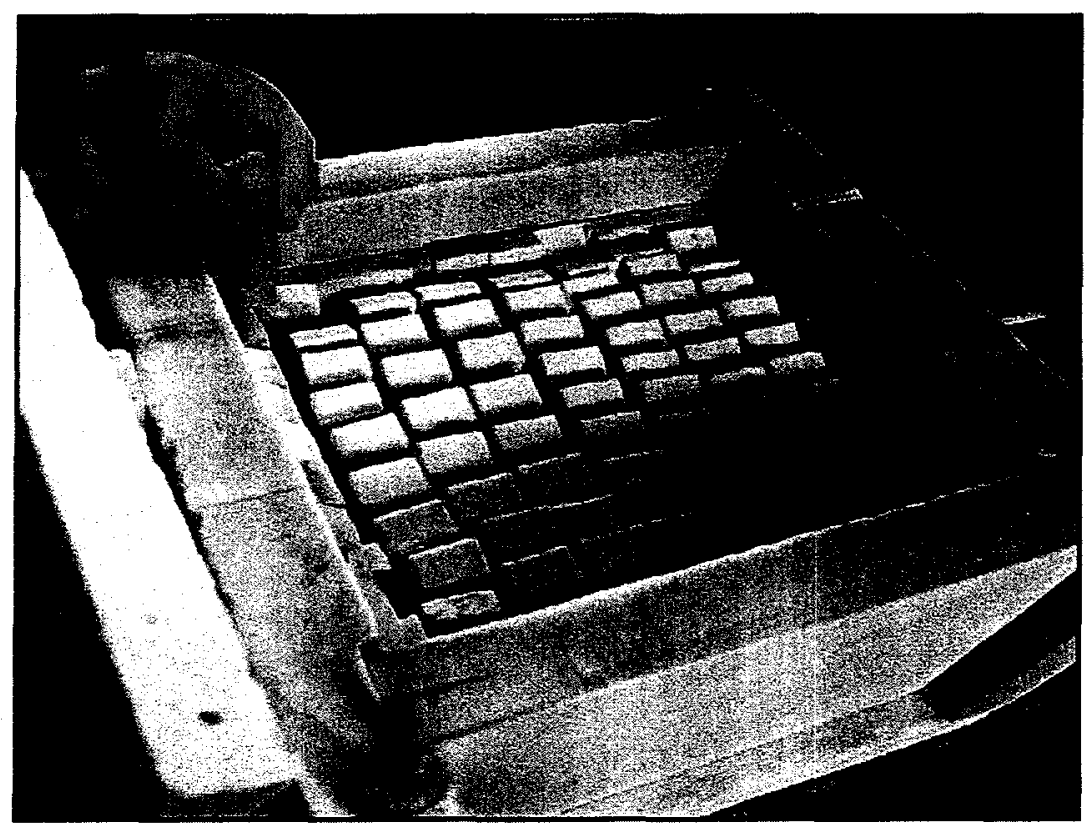

Figure 16. Photo showing the top layer (two total) of samples in which 125 samples (5.8 $\mathrm{kg}$ ) nitrided using $\mathrm{MW}$ heating. 


\section{DISTRIBUTION}

1. S. Diamond, Department of Energy, Office of Heavy Vehicle Technology (EE-33), 1000 Independence Avenue, S.W., Washington, D.C. 20585

2. P. L. Gorman, Department of Energy, Oak Ridge Operations Office, Post Office Box 2008, Oak Ridge, Tennessee 37831-6269

3. B. Mikijelj, Ceradyne, Inc., 3169 Red Hill Avenue, Costa Mesa, California 92626

4-5. Office of Scientific and Technical Information, Post Office Box 62, Oak Ridge, Tennessee 37831

6. R. L. Beatty

7. R. A. Bradley

8. D. F. Craig

9. R. G. Gilliland

10. D. R. Johnson

11. J. O. Kiggans, Jr.

12. R. J. Lauf

13. A. J. Luffman

14-19. T. N. Tiegs

20. C. A. Valentine

21. Laboratory Records - RC 